\title{
A Qualitative Study of the Enterprise Resource Planning (ERP) System Implementation-Related Factors: A Case Study Approach
}

\section{Dr. Almahdi M. S. Ibrahim}

Sebha University, Libya

\section{Abstract}

Enterprise Resource Planning System (ERP) is a business management system that comprises integrated sets of comprehensive software, it can manage and integrate all the business functions within an organization (Shehab et al., 2004). Many companies have made considerable investments in ERP installation systems in order to maintain

Corresponding Author: Dr. Almahdi M. S. Ibrahim almahdielgadi@hotmail.com

Received: 23 April 2018 Accepted: 8 May 2018 Published: 4 June 2018

Publishing services provided by Knowledge E

(c) Dr. Almahdi M. S

Ibrahim. This article is

distributed under the terms of

the Creative Commons

Attribution License, which

permits unrestricted use and redistribution provided that the original author and source are credited.

Selection and Peer-review under the responsibility of the IRCHE 2017 Conference Committee.

\section{G OPEN ACCESS} good performance. The aim of this paper is to demonstrate the contribution of qualitative methods and techniques in extending the understanding of the research methodology used to implement an Enterprise Resource Planning System in the case study organisations in Libya. It discusses the issues related to research design and the reasons for choosing the case study approach, as well as the instrument development process. The originality of this paper, that triangulation has not been used extensively in case study research, nor has a multiple case study approach been commonly applied. This paper deconstructs the methods and their subsequent contribution to the findings of this study.

Keywords: Qualitative Research, Research Methodology, case study, Enterprise Resource Planning (ERP).

\section{Introduction}

A research methodology is a systematic and orderly approach taken towards the collection and analysis of data (Collis and Hussey, 2003). This paper describes the research methodology employed for meeting the objectives of the study. In particular reference will be made to the overall research process and model as well as the research strategy and research methods used, along with the rationale behind making specific choices. In addition, this paper also discusses the development of the research instrument and its pilot implementation. 


\section{The Research Model}

In this section the research process adopted for this study is discussed in detail. Issues related to the research philosophy, research approach, research strategy and data collection are sequentially discussed and their relevance to this research is examined in detail in order to support the relevant choices made.

\section{Research Philosophy}

The concept of research philosophy refers to the progress of scientific practice based on people's views and assumptions regarding the nature of knowledge. There are two main views on the nature of knowledge: the positivism paradigm and the phenomenological one. According to the former, knowledge is viewed as objective and external to social constructs. According to the later though, knowledge is socially constructed and subject to alterations depending on time and the environment concerned. The research philosophy adopted in this project is the phenomenological paradigm, in the sense that the researcher interacted with some case study organisations in order to explore the situation of interest. The phenomenological paradigm refers to the subjective aspects of human activity by focusing on the meaning rather than the measurement of social phenomena. The main reason for using the phenomenological paradigm is that the subject under investigation is not supported by an extensive theoretical background (Creswell 1994; Patton 1990). This study was essentially based on qualitative data from two cases, the selection of small samples, and a rich understanding of the phenomena related to soft ERP factors in the environment of the Libyan oil sector. Moreover, the area under investigation is not well understood, due to the originality of this research paper and a lack of focused previous research on this subject. Consequently, a case study approach allowed the development of an understanding of all the important relevant factors (Almahdi, 2013b). The case study approach is methodologically recommended for areas that are not well theorised.

\section{Research Approach}

The two main research methodological approaches are deductive and inductive one. The deductive approach traditionally implies an inquiry into an identified problem based on the testing of a theory. The deductive approach moves from theory to its empirical investigation. The inductive approach is generally an inquiry to understand 
a social or human problem from multiple perspectives (Yin, 1994), and it starts with an empirical investigation of a rather under-theorised area in order to develop corresponding theory. The selection of an appropriate research method is critical to the success of any research project, and must be driven by the research questions and the status of knowledge in the area being researched. As discussed above, a combination of research methods may be more effective in order to achieve specific research objectives.

\section{Research Strategy}

A qualitative case study methodology has been used for the data collection in order to gain insights into the topic investigated (Yin, 1994). In case studies, the researcher explores a bounded phenomenon (by time, place, and activity) and collects detailed information through a variety of data collection procedures over a sustained period of time. According to Lubbe (2003), case studies may be used to develop theoretical conjecture regarding the formulation, adaptation and implementation of Information Technology (IT) and its benefits.

As discussed above, case studies are often employed in Information System (IS) and Information Technology (IT) research (Lee, 1989; Irani et al., 1999; Almahdi 2013 a and Asniati et al., 2015). Indeed, Klein and Myers (1999) pointed out that the case study research methodology is now accepted as a valid research strategy within the IS research community. Moreover, Irani et al. (1999, p. 190) claimed that "A case study strategy as part of an Information Systems (IS) research methodology embodies a unique style and is one which can employ a variety of research methods". In both IT and IS, there has been a general shift of research from the technological to the managerial aspects; hence the increasing interest in the application of a more qualitative research approach (Myers, 1997). The purpose of the case study was to enable the investigator to focus on specific questions regarding the soft factors of ERP implementation and to gain knowledge of the real attitudes of top management, managers at different levels, technicians, end-users and employees to such factors. The case study is used as the best means to achieve the maximum knowledge and understanding of factors related to ERP implementation.

A multiple case studies approach was adopted for the purposes of the research. The cases are the Arabian Gulf Oil Company and the Waha Oil Company. 


\section{Justifications for Choice of Case Study Organisations}

Based on the discussions above and Yin's (2003) argument that "The criticisms may turn into scepticism about the ability to do empirical work in a single case study" (p.54). Having two cases can overcome such criticisms. Therefore, it was decided to use two case studies. The cases used for this research are two Libyan oil organisations: the Arabian Gulf Oil Company and the Waha Oil Company. The reasons for selecting these particular cases are discussed below:

The Arabian Gulf Oil Company has already implemented ERP software, consisting of three main functions: human resources; accounting and materials.

The Waha Oil Company uses some software applications and it is in the process of implementing an ERP system.

Both companies are the first companies to implement ERP in the Libyan oil sector.

Permission was granted by the National Oil Corporation (NOC) and the case study companies for conducting this study of both companies.

The Arabian Gulf Oil Company and the Waha Oil Company are the biggest oil companies in Libya. They are strategically important in Libya's oil sector, and hence to the country's economy. Through the National Oil Corporation, which belongs to the Ministry of Energy, the government has advised these companies to implement ERP in order to gain the benefits of using such systems.

The companies were chosen because they are situated in Tripoli, Libya's capital city, and Benghazi, the second largest city of Libya. This feature allowed the researcher to contact them easily and considerably reduce travelling time. The companies were chosen because they are situated in Tripoli, Libya's capital city, and Benghazi, the second largest city of Libya. This feature allowed the researcher to contact them easily and considerably reduce travelling time.

\section{Data Collection Methods}

No single source of data has a complete advantage over others, while the combination of multiple sources of evidence can help to clarify the real meaning of the phenomenon being seen (Yin, 2003). The following are the data sources selected for this research.

Interviews: In this study, a semi-structured interview was used as the main instrument for data collection purposes. One advantage of the semi-structured interview is 
the flexibility to explore areas as they arise during the interview process. The questions that have been used in the interviews were developed based on the theoretical framework. Open-ended interview questions were asked to respondents in order to gain insight into the subject investigated.

Documents: Documents were also used for data collection purposes in this research paper. They could be letters, memoranda, agendas, administrative documents, newspaper articles, study reports, or any document that is germane to the investigation (Tillis, 1997). One of the most important uses of documents is to corroborate evidence gathered from other sources. The potential for over-reliance on documents as evidence in case studies has, however, been criticised (Tillis, op. cit.), especially if the researcher is inexperienced and mistakes some types of documents for unmitigated truth (Yin, 1994). Relevant documents used in this research included records, files, minutes of meetings, newsletters, articles, unpublished referenced documents and correspondence and reports concerning different parts of the case study companies.

Observation: Observations usually provide and reconfirm important information from interview results. According to Bocij et al. (2003) the benefits that may be gained from observation are as the ability to see how documents and records are actually handled and processed, observation may give a greater insight into the actual business operations than simple paper documentation, identification of particular operations that take a long time and the opportunity to see how different processes interact with each other, thus giving the researcher a dynamic rather a static view of the business situation under investigation. It may be argued that observation as a data collection method may lack validity and reliability. This is true if observations are used as a single method of data collection, which of course is not the case in this research.

\section{Sampling Strategy}

Purposeful sampling has been used as the most appropriate sampling method regarding the selection of the participants. Respondents (senior managers, middle managers, IT technicians, and end-user employees) involved in the ERP project were interviewed. In discussing the main differences between quantitative and qualitative methods in connection with the most suitable sampling methods, Irani et al. (1999) claimed that a sample in quantitative research should be carefully chosen and pre-defined. Whereas, in quantitative research sampling should be determined by whom researcher meets during field-work. Patton (1990) claims that quantitative methods typically rely on large sample sizes which are taken randomly. In contrast, qualitative research normally 
relies on relatively small in-depth samples or even single cases that are selected purposefully. Respondents at different hierarchical levels of the Arabian Gulf Oil Company and the Waha Oil Company were considered for the purpose of this research. It was found that 66 people were involved in the ERP project in the two companies. As some people in both companies were away for different reasons (time constraints, substantial workloads, being abroad and annual leaves), a total of 56 interviewees were targeted.

Even greater attention was paid to the selection of respondents with the objective to ensure the collection of information that was as unbiased as possible from a qualitative sample. It was clear that additional interviews could be required in some cases in order to gain more relevant information regarding the subject investigated.

\section{Data Analysis}

Data analysis comprises examining, categorising, tabulating, and interpreting the evidence to support, reject or amend a theory and/or to generate new theory. In order to deconstruct the data, explore the underlying meanings and to generate theory, Huberman and Miles (1994) propose the stages for qualitative data analysis as data reduction, data display and conclusion drawing and verification. At the early stage of the data reduction process, the researcher experienced what Huberman and Miles (op. cit.) describe as a situation where everything looks important. However, the experience gained in the pilot study showed how to deal with unnecessary information in order to keep a focused approach and to distinguish between relevant and irrelevant information. The researcher was sufficiently confident regarding his degree of familiarity with data only after reading the transcripts frequently and thoroughly. This helped to develop an improved awareness in deciding which data was more important. Abstracting and putting data into meaningful and related categories was the most important stage of data reduction. Keeping in mind the aim and objectives of this research, the compressed data was organised into written records, and then the data collected were grouped into categories according to themes.

Data display was made easier through the application of the research. During the pilot study, a trial run of the analysis process had been exercised, so that as the data display process progressed; grouping data under the three main types of factors enabled major themes to be identified, which allowed the vast amount of data to be classified, providing a valuable basis for the drawing of conclusions. The researcher was explicitly trying to detect any possible previously unreported factors related to 
the implementation of an ERP system which might emerge during the data analysis were sought.

The next important stage of the research is drawing conclusion and verification. This refers to a process of developing an initial thought about patterns and explanations from the findings, verifying them constantly by checking the data, and forming a new matrix of understanding. It is through such a process that the validity of the data can be established and that the meaning of the findings emerges. Subsequent to the process of conclusion drawing and verification, the researcher strove to apply meanings and explanations to the data. Throughout this process, possible links between the different factors and implementation stages were developed.

The outcome of these considerations with regards to data reduction, display, and analysis, and finally the conclusions drawn are presented.

\section{Instrument Development}

In formulating appropriate questions, the guidelines given in Tellis (1997) and Saunders et al. (2003) were considered in detail. They recommended that three types of questions may be used in semi-structured interviews:

- Open questions that help to define and describe a situation or event.

- Probing questions that can be used to explore responses that are of significance to the research topic.

- Specific and closed questions that may be used to obtain specific information or to confirm a fact or opinion.

Open-ended questions were used to develop the research instrument. By using this type of semi-structured interview questions the respondents were asked to comment about the subject investigated, and to provide insights into the subject. The different questions regarding the three main factors followed directly from the factors identified in the theoretical framework and were also based on a review of the literature on factors in ERP implementation. The interview questions were specifically devised from elements of the theoretical framework. The questions developed were used to get the data required from the case study organisations and to ensure all relevant issues were covered. The official language in Libya is Arabic and consequently the initial instrument needed to be translated into that language to allow the collection of data. The researcher and a bilingual Arabic/English IT manager carefully performed the translation of the instrument. The respondents were then asked the questions and 
replied in their mother tongue. This enabled them to optimise the verbalisation of their accounts. For the purpose of the analysis, the interviews in Arabic were translated into English and then back into Arabic in order to minimise any misunderstandings arising from inaccurate translation.

\section{Pilot Implementation}

Conducting a pilot study before the main study allows any potential problems in the pro forma of the interview to be identified and corrected (Gill and Johnson, 1997). The aim of this pilot study was to provide a clear understanding of any potential problems which the questions and to ensure the appropriateness of the research instrument. In addition, the pilot study enabled a preliminary understanding of soft ERP implementation related-factors in the Libyan oil industry to be developed. The rationale behind the pilot study was to provide a more valid and reliable instrument, to practise the process of the qualitative interviews and data analysis process. The initial outcomes of the pilot study analysis enabled an enhanced understanding of the subject to be gained in the specific context of the companies. The pilot study results, therefore, contributed to an improved awareness of potentially important issues regarding soft ERP implementation related-factors. These initial results also helped the researcher to conduct the interviews in the main fieldwork with more confidence, and to measure the time required for interviews. Interview duration in the pilot study was between 34 and 55 minutes, averaging 50 minutes. This helped the actual data collection process to be scheduled.

In summary, the pilot study was an essential element of this research, in order to ensure that the interview questions were clear and made sense to the respondents. Moreover, the pilot study was important in terms of measuring the time needed for interviews, and it was a valuable initial opportunity to test the validity of the research questions. In more practical terms, the pilot study provided the opportunity to practise the analysis of data.

\section{Case Study Implementation}

Information was collected by means of conducting interviews and observation, and by reference to relevant documents. All interviews were conducted on the premises of the companies involved. The interviews involved no interruptions and the respondents had sufficient time to develop their arguments and give appropriate detailed information. 
The numbers of interviewees in the two case study organisations were 32 and 23 respectively. The respondents included staff from top and middle management, IT technical support and end-users of the system. Covering these four levels enhanced the validity by getting responses from different points of view from the respondents. Open-ended questions were asked at different respondents, these questions allowed flexibility and provided the possibility of in-depth study, and which also enabled the interviewer to clear up any misunderstandings (Verville and Halingten, 2002). All the interviews were conducted in a similar way. The interviewees were given a description of the research purpose at a confirmation meeting. This helped in the understanding of the questions, made respondents more relaxed and comfortable, so that they gave more sincere answers, and respondents were allowed to make comments regarding the questions before conducting the interviews. Furthermore, this provision may have also promoted the validity and of data by enabling the interviewees to consider the information being requested. Documentation results were used before the interviews to avoid time-wasting through the repetition of questions when the answer were already known through such documentation. Interviewees in both case study organisations were prepared for the researcher to return later to gain further information, and some spent time with the researcher out of working hours. This increased levels of confidence in the accuracy of the interview data. No interviews were tape-recorded, because the respondents did not want their interviews to be recorded. This may be due to cultural and political considerations. To reduce the risk of misunderstanding to an absolute minimum, all interviews were conducted in the respondents' and researcher's first language. Copious notes were taken during each interview, in order to collect the relevant information. Notes from interview were later converted into some form of written record on the same day. This method is suggested by Huberman and Miles (1994).

As documentation may help to provide very useful information, special attention was directed to the relevant review process. Files, minutes of meetings, articles, unpublished referenced documents and correspondence and reports concerning different levels of the company and newsletters related to the implementation of ERP in both case studies were examined. Both case study organisations had similar types of documentation relating to some or all of their business operations. This documentation helped provide background information relating to the subject under consideration and enabled the interviews to be conducted in a more effective way.

Direct observation as a method of collecting data is associated with either a positivistic or phenomenological methodologies (Collis and Hussey, 2003). This method 
was also used for data collection. The benefits of observation were that the researcher could see directly how the ERP system was working in the Arabian Oil Golf Company and how the project teams conducted meetings in both companies.

Reliability refers to whether research methods can be replicated by others (Yin, 1994). Because of the uniqueness of the case study, and the timeframe, the exact replication of this study would be difficult. However, the methods of qualitative research and documentation used in this research may make the research replicable to some extent. Regarding construct validity, the research was designed to maximise the use of multiple sources of evidence. Careful specification of the units of analysis increased internal validity. External validity was increased through careful attention to the criteria for selection in the case study organisations. Finally, external validity also refers to whether research findings can be generalised to other situations (Yin, 2003). Qualitative approaches and the use of case studies are less generalisable because they cannot easily be considered representative of a population (Irani et al., 1999). This research investigates the 'soft' ERP implementation related factors in Libyan oil companies, and the findings of this research are consequently less generalisable to other situations.

\section{Conclusions}

This paper has provided an overview of the research methodology. The broad aim of this paper is to demonstrate the contribution of qualitative methods and techniques in extending the understanding of the research methodology used in implementing an ERP system in oil companies in Libya. On the basis of the main aim and objectives, a multiple case studies approach was used for the purpose of answering the specified research questions, whereas semi-structured interviews, documentation review and observation have been chosen for the data collection process. The use of a variety of research methods aimed to achieve the triangulation of data and therefore reduce bias. The research process model and progress has also been given. Finally, this paper presented the instrument development based on the research objectives, and the pilot study has been addressed to provide clear understanding about the research problems.

\section{References}

[1] Almahdi M. S. I. (2013a). Factors of Enterprise Resource Planning System (ERP) Implementation in a Libyan Oil Company, The International conference Information Systems 2013, Lisbn, Portugal. 
[2] Almahdi M. S. I. (2013b). Using Case Study and Triangulations as A Part of an Enterprise Resource Planning System Research Methodology, Information Systems Post-implementation and Change Management 2013 (ISPCM 2013) Conference, Prague, Czech Republic.

[3] Asniati, B., Efa. Y., and Amsal. (2015). ERP System Implementation Readiness: The Case of Government Organizations in Indonesia. Australian Journal of Sustainable Business and Society, 1(1), pp. 54-65.

[4] Bocij, P., Chaffey, D., Greasley, A. and Hickie, S. (2003). Business Information Systems, 2nd Edition, Pearson Education Limited, Edinburgh.

[5] Collis, J. and Hussy, R. (2003). Business Research, 2nd Edition, Palgrave Macmillan, Basingstoke.

[6] Creswell, J. W. (1994). Research design: Qualitative and Quantitative Approaches, Sage Publications, London.

[7] Gill, J. and Johnson, P. (1997). Research Methods for Managers, 2nd Edition, Paul Chapman Publishing Lit, London.

[8] Huberman, A.M. and Miles, M. (1998). Data Management and Analysis Method in Denzin and Lincoln, Collecting and Interpreting Qualitative Materials, Sage Publication, London.

[9] Irani, Z., Ezingeard, J-N., Grieve, R.J. and Race, P. (1999). A case Study as Part of An Information Systems Research Methodology: A critique, International Journal of Computer Application in Technology, 12 (2), pp. 190-198.

[10] Klein. H.K. and Myers. M.D. (1999). A Set of Principles for Conducting and Evaluating Interpretive Field Studies in Information Systems. MIS Quarterly, 23 (2), pp. 67-93.

[11] Lee. A.S. (1989). A Scientific Methodology for Management Information Systems Case Studies. MIS Quarterly, 13 (1), pp. 33-50.

[12] Lubbe. S. (2003). The Development of A case Study Methodology in The Information Technology (IT) Field: A Step by Step Approach, ACM International Conference Proceeding Series, New York, USA.

[13] Myers. M.D. (1997). Qualitative Research in Information System, MIS Quarterly, 21 (2), pp. 241-242.

[14] Patton. M. Q. (1990). Qualitative Evaluation and Research Methods, 2nd Edition, Sage Publication. Newbury Park.

[15] Saunders, M., Lewis, P. and Thornhill, A. (2003). Research methods for business students, 3rd Edition, Peason Education Limited, Edinburgh. 
[16] Shehab, E.M., Sharp, M.W., Supramaniam, L. and Spedding, T.A. (2004). Enterprise Resource Planning An integrative Review, Business Process Management Journal, 10 (4), pp. 359-386.

[17] Tellis. W. (1997). Application of a Case Study Methodology, The Qualitative Report, 3 (3). pp. 1-7.

[18] Verville, J. and Halingten. (2002). An Investigation of The Decision Process for Selecting an ERP Software: The Case of ESC, Management Decision, 40 (3), Pp. 206-216.

[19] Yin, R. (2003). Case Study Research Design and Methods, Applied Social Research.

[20] Yin. R. (1994). Case Study Research Design and Methods, 2nd Edition. Sage Publications, Newbury Park. 